\title{
An unexpected role for a Wnt-inhibitor: Dickkopf-1 triggers a novel cancer survival mechanism through modulation of aldehyde-dehydrogenase-1 activity
}

\author{
U Krause $^{1,2}$, DM Ryan $^{3}$, BH Clough $^{1}$ and CA Gregory ${ }^{*, 1}$
}

It is widely accepted that canonical Wnt (cWnt) signaling is required for the differentiation of osteoprogenitors into osteoblasts. Furthermore, tumor-derived secretion of the cWnt-antagonist Dickkopf-1 (Dkk-1) is known to cause bone destruction, inhibition of repair and metastasis in many bone malignancies, but its role in osteosarcoma (OS) is still under debate. In this study, we examined the role of Dkk-1in OS by engineering its overexpression in the osteochondral sarcoma line MOS-J. Consistent with the known role of Dkk-1 in osteoblast differentiation, Dkk-1 inhibited osteogenesis by the MOSJ cells themselves and also in surrounding tissue when implanted in vivo. Surprisingly, Dkk-1 also had unexpected effects on MOSJ cells in that it increased proliferation and resistance to metabolic stress in vitro and caused the formation of larger and more destructive tumors than controls upon orthotopic implantation. These effects were attributed in part to upregulation of the stress response enzyme and cancer stem cell marker aldehyde-dehydrogenase-1 (ALDH1). Direct inhibition of ALDH1 reduced viability under stressful culture conditions, whereas pharmacological inhibition of cWnt or overexpression of ALDH1 had a protective effect. Furthermore, we observed that ALDH1 was transcriptionally activated in a c-Jun-dependent manner through a pathway consisting of RhoA, MAPkinase-kinase-4 and Jun N-terminal Kinase (JNK), indicating that noncanonical planar cell polarity-like Wnt signaling was the mechanism responsible. Together, our results therefore demonstrate that Dkk-1 enhances resistance of OS cells to stress by tipping the balance of Wnt signaling in favor of the non-canonical Jun-mediated Wnt pathways. In turn, this results in transcriptional activation of ALDH1 through Jun-responsive promoter elements. This is the first report linking Dkk-1 to tumor stress resistance, further supporting the targeting of Dkk-1 not only to prevent and treat osteolytic bone lesions but also to reduce numbers of stress-resistant tumor cells.

Cell Death and Disease (2014) 5, e1093; doi:10.1038/cddis.2014.67; published online 27 February 2014

Subject Category: Cancer Metabolism

Osteosarcoma (OS) is a tumor of bone that usually affects children. Approximately 3000 new cases were estimated in the United States in 2012. ${ }^{1}$ Although it is a diverse disease with multiple histological and clinical subtypes, the main hallmark of OS is the aberrant osteoblastic and/or chondrogenic differentiation of mesenchymal stem cells (MSCs).

One of the key mechanisms for control of MSC proliferation and differentiation is the canonical Wnt-signaling (cWnt) pathway. ${ }^{2,3}$ In this pathway, Wnt ligands bind to receptors frizzled (Frz) and low-density lipoprotein receptor-related protein (LRP) 5/6. The co-receptor complex recruits the cytoplasmic protein disheveled (Dsh) to initiate a cytoplasmic cascade resulting in the inhibition of glycogen-synthetasekinase-3 $\beta$ (GSK3 $\beta)$. With GSK3 $\beta$ sequestered in an inactive form, phosphorylation and proteosomal degradation of the cotranscription factor $\beta$-catenin are inhibited resulting in raised cytosolic levels. Upon entry into the nucleus, $\beta$-catenin acts as a nuclear enhancing factor and promotes osteogenic differentiation. One of the most potent extracellular inhibitors of cWnt-signaling is Dickkopf-1 (Dkk-1), and, when present in high concentrations, bone homeostasis shifts in favor of the catabolic axis. ${ }^{4}$ Indeed, high serum levels of Dkk-1 were linked to increased osteolysis in multiple myeloma ${ }^{5}$ and were found in sera of patients newly diagnosed with OS. ${ }^{6}$ Furthermore, Dkk-1 has been reported to have a role in the engraftment of metastatic cells to bone in prostate and breast cancer. ${ }^{7,8}$

Contrary to established literature supporting cWnt-signaling as oncogenic, ${ }^{9}$ the roles of Wnts and their inhibitors are controversial in bone tumors with a growing body of evidence, suggesting that Wnt inhibition can exacerbate OS. For example, inactive cWnt-signaling has been correlated to malignancy, ${ }^{10}$

\footnotetext{
${ }^{1}$ Institute for Regenerative Medicine at Scott and White Hospital, Texas A\&M Health Science Center, Module C, Temple, TX, USA; ${ }^{2}$ Department of Orthopaedics, Scott and White Hospital, Texas A\&M Health Science Center College of Medicine, Temple, TX, USA and ${ }^{3}$ Center for Gene Therapy and Department of Medicine, Tulane University Health Sciences Center, New Orleans, LA, USA

*Corresponding author: C Gregory, Institute for Regenerative Medicine, Texas A and M Health Science Center, Module C, 5701 Airport Road, Temple, TX 76502 , USA. Tel: +1 254771 6816; Fax: +1 254771 6839; E-mail: cgregory@medicine.tamhsc.edu

Keywords: osteosarcoma; Wnt-signaling; Dkk-1; MOS-J; ALDH1

Abbreviations: 7-AAD, 7-aminoactinomycin D; ALDH, aldehyde-dehydrogenase; ALP, alkaline phosphatase; BIO, 6-bromoindirubin- 3'-oxime; CP, chloramphenicol; CSC, cancer stem cell; cWnt, canonical Wnt; DAPI, 4',6-diamidino-2-phenylindole; DEAB, diethylaminobenzaldehyde; Dkk-1, Dickkopf-1; DMSO, dimethyl sulphoxide; FBS, fetal bovine serum; GSK3 $\beta$, glycogen synthetase kinase-3 $\beta$; JNK, Jun-N-terminal kinase; $\mu \mathrm{CT}$, micro-computed tomography; NDGA, nordihydroguaiaretic acid; OS, osteosarcoma; Qrtpcr, quantitative real-time PCR; TNKilll, tankyrase inhibitor III; ROI, region of interest

Received 04.11.13; revised 23.1.14; accepted 24.1.14; Edited by G Raschellá
} 
MSC transformation ${ }^{11}$ and prostate cancer metastasis. ${ }^{12}$ In contrast, inactive or inhbited cWnt-signaling has been reported to decrease tumorigenesis and metastasis. ${ }^{13-16}$

In an attempt to resolve these controversies, we speculated that Wnt-inhibitors exert contrasting effects on the tumor and surrounding stroma. Specifically, they may slow tumor cell proliferation, but their potent osteo-inhibitory effects on the stroma could exert a protective effect by maintaining the tumor niche. To this end, we examined the effects of the Wntinhibitor Dkk-1 on the phenotype of the well-differentiated and modestly malignant murine osteochondrosarcoma cell line MOS-J. ${ }^{17}$

We stably introduced a single gene, human Dkk-1, and characterized the resulting cells in vitro and in vivo. As expected, Dkk-1 expression reduced the cells' capacity for osteogenic differentiation in vitro and in vivo, but it also increased proliferation, resistance to metabolic stress and the capacity for osteolytic tumorigenesis in vivo. These observations were attributed to upregulation of the stress response enzyme and cancer stem cell marker aldehyde-dehydrogenase-1 (ALDH1). The results herein support a mechanism whereby Dkk-1 enhances resistance of OS cells to stress by tipping the balance of Wnt-signaling in favor of the Junmediated noncanonical Wnt pathways. In turn, this results in the activation of RhoA, JNK, and transcriptional activation of ALDH1 through Jun-responsive promoter elements. These data not only support the targeting of Dkk-1 to prevent and treat osteolytic bone lesions but also to deplete stressresistant tumor cells.

\section{Results}

Transfection of MOS-J cells. Full-length cDNA encoding the human Dkk-1 gene was cloned into pLenti6.1 and orientation was confirmed. Lentiviral transduction using standard protocols resulted in an unsatisfactory yield of transductants (less than 1\%). In order to achieve stable gene expression at higher yields, murine MOS-J cells were transfected with plasmids encoding Dkk-1 or control vector by nucleofection. Fluorescently labeled control and Dkk-1expressing sublines were generated by lentiviral transduction of a construct constitutively expressing dsRedMito. Hereafter, Dkk-1-expressing MOS-J cells are referred to as MOSJ-Dkk1 cells and controls will are referred to as MOSJ-pLenti cells.

Effect of Dkk-1 overexpression on MOS-J cells in vitro. To confirm that Dkk-1 was secreted from the MOSJ-Dkk1 cells, it was measured in conditioned media by ELISA. A time-dependent increase of Dkk-1 in MOSJ-Dkk1 supernatants was observed, which reached a plateau of $3 \mu \mathrm{g} / \mathrm{ml}$ after 7 days, indicative of steady-state production and degradation of Dkk-1. Although there is $30 \%$ cross-reactivity between human and murine Dkk-1 protein in this assay, no Dkk-1 could be detected from control MOSJ-pLenti cells (Figure 1a). Our group has reported that Dkk-1 has a transient role in cell-cycle initiation in $\mathrm{MSCs}^{18}$ and we observed a similar effect on MOSJ-Dkk1 cells. However, whereas the cell-cycle promoting effect of Dkk-1 in MSCs is transient and rapidly downregulated as cells expand, it was constitutively active in the case of MOSJ-Dkk1 cells, resulting in faster expansion of cultures when compared with the control cell line (Figure 1b). This was confirmed by 5-ethynyl-2'-deoxyuridine (EdU) incorporation (Supplementary Figure S1a).

In order to examine whether the secreted Dkk-1 can effectively disrupt cWnt-signaling in an autocrine manner, cytosolic $\beta$-catenin levels were assessed by immunoblotting. In MOSJ-Dkk1 cells, cytosolic and nuclear $\beta$-catenin levels were diminished, suggesting that Dkk-1 is functionally active and triggers its degradation consistent with inhibited cWntsignaling (Figure 1c, Supplementary Figure S1b).

In osteoprogenitors, cWnt-signaling positively regulates osteogenic differentiation. ${ }^{18-20}$ Therefore, MOSJ-Dkk1 cells would be expected to possess impeded osteogenic capacity when compared with controls. To explore the differentiation capacity of MOSJ-Dkk1 and MOSJ-pLenti cells in vitro, we performed alkaline phosphatase (ALP) assays on cultures in the presence of osteogenic factors, ascorbic acid and $\beta$-glycerophosphate. ${ }^{21}$ Control MOSJ-pLenti cells exhibited a relatively high level of ALP activity that could not be substantially elevated by osteogenic supplementation. The nonstimulated ALP activity in MOSJ-Dkk1 cells was approximately $20 \%$ of the controls, but, in this instance, it could be enhanced to $50 \%$ of the MOSJ-pLenti levels by osteogenic supplementation (Figure 1d). Next, we examined whether the MOSJ lines had the capacity to adopt a mineralizing phenotype by adding dexamethasone to the media. ${ }^{22}$ Dexamethasone-treated MOSJ-pLenti cells formed a mineralized monolayer within 2 weeks, but in accordance with our previously published data ${ }^{6}$ this was completely ablated in MOSJ-Dkk1 cells, presumably due to the inhibitory effects of Dkk-1 (Figure 1e). These data therefore demonstrate that Dkk-1 has the expected osteo-inhbitory effect in vitro. During the mineralization studies, we observed that upon extended confluency, MOSJ-pLenti monolayers frequently exhibited areas of detachment and cell death that did not occur in the MOSJ-Dkk1 cultures. This apparent culture instability could be observed with the otherwise contact-inhibited parental cell line, too, as previously reported. ${ }^{17}$

The phenomenon was investigated in more detail by observing confluent cultures in the absence of osteogenic supplementation. After extended confluency, under otherwise stable conditions and frequent media changes, many of the MOSJ-pLenti control cells showed classical signs of apoptosis and died (Figure 1f, Supplementary Figure S2). In contrast, the MOSJ-Dkk1 cells not only survived this challenge, forming and maintaining a stable confluent monolayer, but also continued to undergo frequent cell divisions that could be observed above the plane of the monolayer (Figure 1f, Supplementary Figure S2).

To quantify these observations, we performed cellcycle and viability assays on post-confluent cultures. The measurements confirmed qualitative observations, in that a greater proportion of MOSJ-Dkk1 cells were actively cycling compared with controls even after 7 days of post-confluence (Figures $2 \mathrm{a}$ and $\mathrm{b}$ ). In contrast, a greater proportion of MOSJpLenti cells accumulated in $\mathrm{G}_{0} / \mathrm{G}_{1}$ phase. In parallel with an increased rate of mitosis, the MOSJ-Dkk1 cells were more resistant to apoptosis as demonstrated by a decrease in the proportion of AnnexinV-positive cells when compared with 


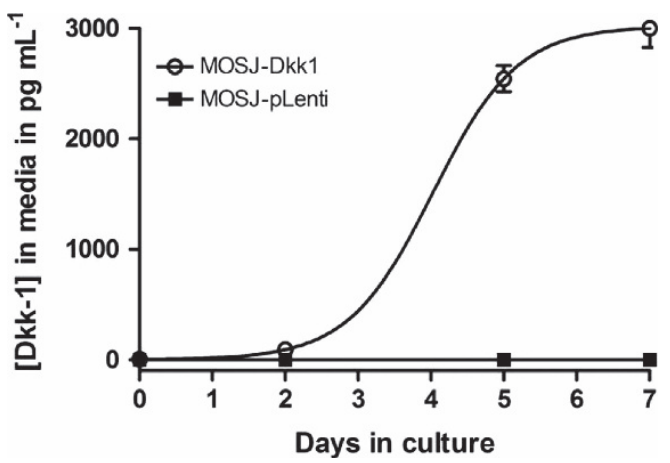

d

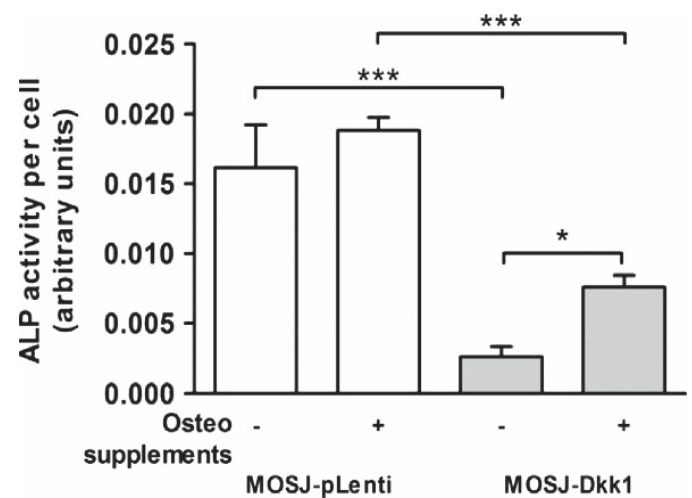

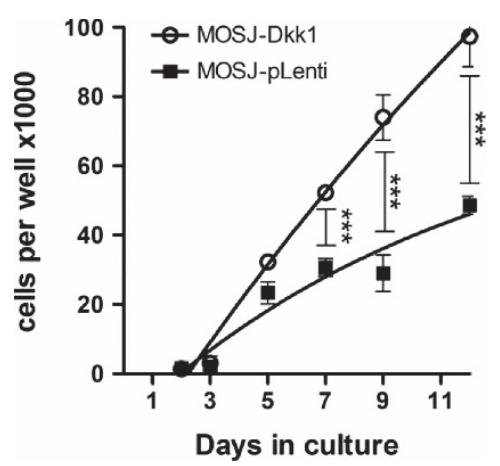

e

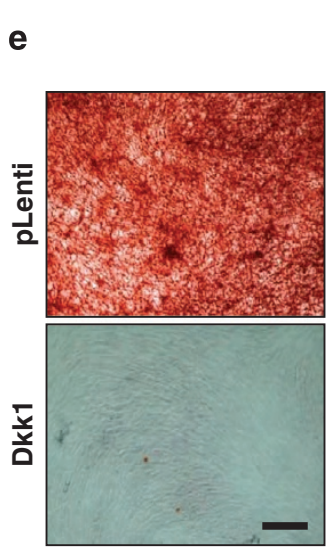

C

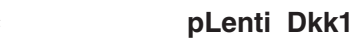

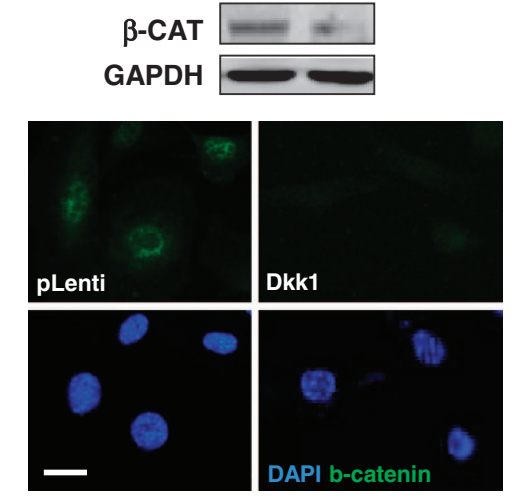

f

f pLenti
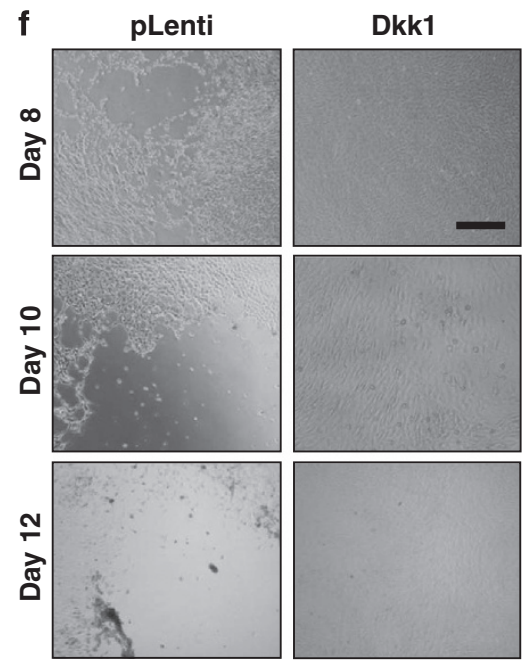

Figure 1 Characterization of MOSJ-Dkk1 cells. (a, b) MOSJ-Dkk1 cells secrete human Dkk-1 into the supernatant (a) and have a growth advantage over MOSJ-pLenti control cells (b) See also Supplementary Figure S1a. (c) Immunoblot (above) demonstrating reduced levels of cytosolic $\beta$-catenin in MOSJ-Dkk1 cells and immunocytochemistry for $\beta$-catenin (below) demonstrating reduced nuclear levels (bar $=10 \mu \mathrm{m}$ ). See also Supplementary Figure S1b. (d) ALP activity is inhibited in MOSJ-Dkk1 cells compared with pLenti controls, but it can be partially recovered by osteogenic supplementation of the media. Cells were cultured in the absence $(-)$ or presence $(+)$ of osteogenic supplements, and ALP activity was measured by colorimetric assay after 8 days. (e) In contrast to MOSJ-pLenti controls, no calcium deposits were evident in osteogenic cultures of MOSJ-Dkk1 stained with Alizarin Red S after 15 days. (f) MOSJ-Dkk1 cells maintain monolayers even after prolonged confluency, whereas pLenti controls undergo apoptosis and detach in large patches. See also Supplementary Figure S2. All experiments were performed in triplicates. Data are means \pm S.D. ${ }^{*} P<0.05,{ }^{* * *} P<0.001$ (ANOVA, Tukey post test). Bars $=100 \mu \mathrm{m}$

MOSJ-pLenti cells (Figures 2c and d). In contrast, the MOSJ-pLenti controls alternated between periods of apoptosis and periods of expansion where the empty areas were repopulated. This is illustrated by a slight increase in the number of cells in S-phase at day 7 post confluency (Figure 2b).

These observations suggest that Dkk-1 not only has profound effects on the differentiation and expansion capacity of MOS-J cells but it also exerts a protective effect. To further examine this apparently novel characteristic of Dkk-1, we performed microarray analyses of confluent cultures of MOSJ-Dkk1 and -pLenti cells. Among the most differentially regulated genes were two aldehyde-dehydrogenase 1 (ALDH1) isoenzymes commonly associated with a prosurvival phenotype. ALDHs are a family of detoxifying enzymes, responsible for the metabolism of destructive freeradicals that occur through the oxidation of lipids, resulting in improved survival. ${ }^{23,24}$ The transcription of $A L D H 1 A 1$ and $A L D H 1 A 7$ was profoundly upregulated on the microarrays
(73- and 10-fold, respectively), and this was confirmed by quantitative RT-PCR (qRT-PCR) (Figure 2e). ALDH1 activity in MOSJ-Dkk1 cells was also measured by using an Aldefluor assay. Approximately $7 \%$ of the MOSJ-pLenti population was ALDH-positive, with a signal above diethylaminobenzaldehyde (DEAB)-inhibitor-treated background levels, whereas $26 \%$ of the MOSJ-Dkk1 cells were positive by this definition. Upon more detailed inspection of the profiles, however, we noted a complete shift in the fluorescence intensity of MOSJDkk1 cells that was not evident with MOSJ-pLenti, suggesting that all MOSJ-Dkk1 cells harbored DEAB-sensitive ALDH activity (Figure 2f).

ALDH has been reported to provide protection against chemical and environmental stress, especially in cancer stem cells (CSCs). We therefore speculated that ALDH was responsible for the enhanced MOSJ-Dkk1 viability. To explore the role of $\mathrm{ALDH}$ in resistance to environmental stress, MOSJDkk1 cells were exposed to ALDH inhibitors chloramphenicol $(\mathrm{CP})^{25}$ or DEAB ${ }^{26}$ and subjected to periods of post-confluent 
culture. Although untreated controls survived 20 days with no significant attrition, there was a dose-dependent cell-death in cultures receiving CP or DEAB (Figures $2 g$ and $h$ ). These results support the role of ALDH in maintaining stress resistance by MOSJ-Dkk1 cells, also suggesting the intriguing possibility that Dkk-1 had initiated a CSC-like phenotype.
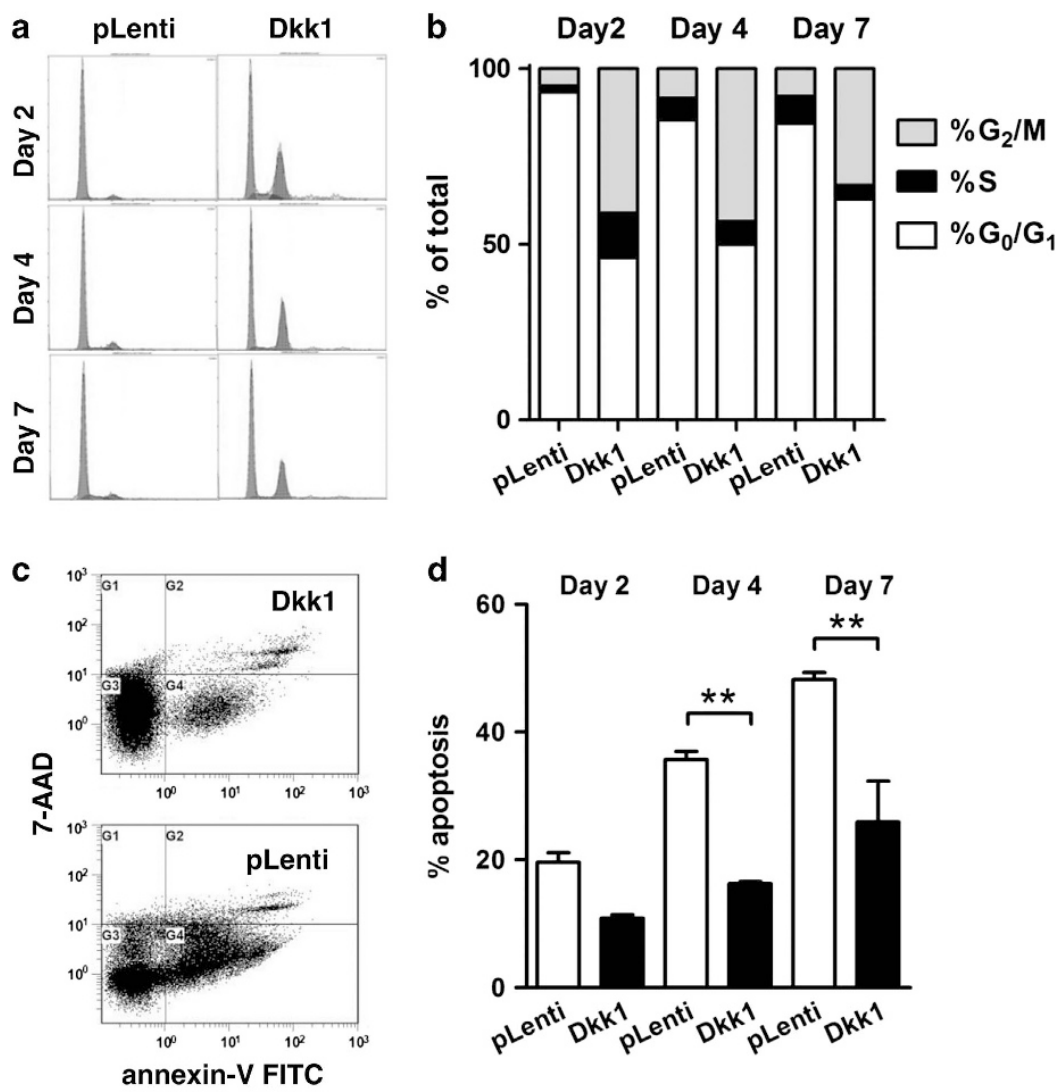

e
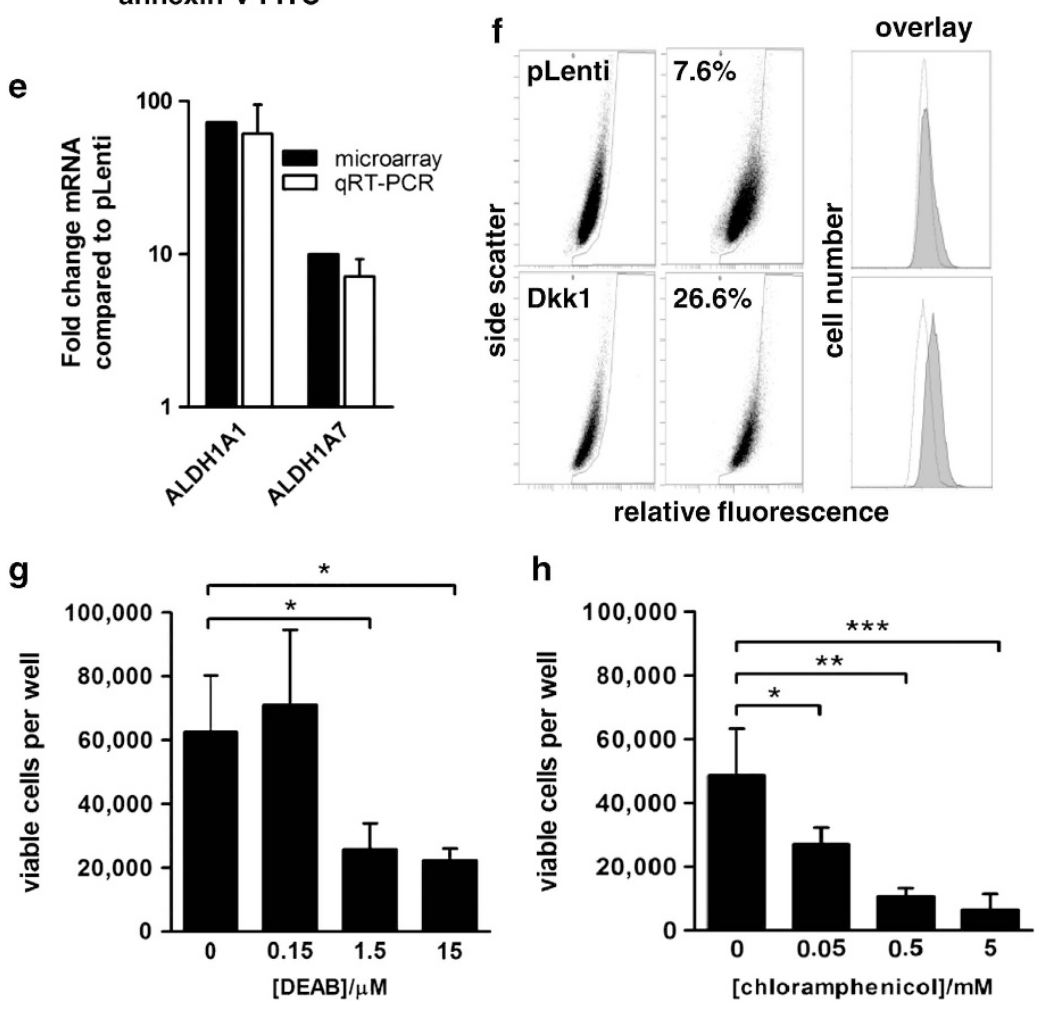
Dkk-1 enhances ALDH1 expression through activation of JNK. To test our hypothesis that, Dkk-1 had induced ALDH expression, we performed RNAi-mediated Dkk-1 knockdown experiments. Using transient siRNA transfections in vitro, Dkk-1 levels in the supernatant of MOSJ-Dkk1 cultures could be substantially reduced (Figure 3a). After 2 days, $A L D H 1 A 1$ and $1 A 7$ transcription was measured by qRT-PCR and found to be downregulated supporting a direct link between Dkk-1 activity and ALDH expression (Figure $3 \mathrm{~b}$ ). To test whether this phenomenon occurred in human OS, two cell lines (SAOS and MG63) known to secrete Dkk-1 were subjected to Dkk-1 blockade (Figure 3a). When Dkk-1 expression was inhibited, ALDH1A1 transcription was reduced in each case (Figure $3 b$ ). ALDH1A7 transcription was not determined due to the absence of its expression in human cells. Interestingly, we noted that, with the exception of SAOS cells, the cell lines that received Dkk-1 blocking RNAi had diminished viability and overall cell recovery when compared with cultures that received scrambled RNAi (Supplementary Figure S3a).

The inverse correlation between ALDH1 expression and cWnt-signaling was explored further by pharmacological modulation. To dismiss the possibility of transfection-induced artifact, or that Dkk-1 was acting on a pathway unrelated to cWnt, we attempted to mimic the effects of Dkk-1 in the parental MOS-J cells with small molecule inhibitors. For this purpose, we utilized CT03477, a small molecule reported to block the interaction between $\beta$-catenin and TCF, ${ }^{27}$ and $a$ tankyrase inhibitor (TNKillI) reported to inhibit the degradation of Axin2 and accelerate degradation of $\beta$-catenin. ${ }^{28-30} \mathrm{MOSJ}-$ pLenti cells were cultured in the presence of $50 \mu \mathrm{M} \mathrm{H}_{2} \mathrm{O}_{2}$ for 2 days or for 20 days in the presence of the agents. Although concentration dependent, approximately twofold more cells survived these conditions when CT03477 and TNKilll were added to cultures at the reported $I_{50} \mathrm{~S}$ (Supplementary Figure $\mathrm{S} 3 \mathrm{~b})$. Furthermore, both agents caused upregulation of $A L D H 1 A 1$ and $A L D H 1 A 7$ (Figure 3c).

We then tested several GSK3 $\beta$-inhibitors in order to re-establish cWnt-signaling and potentially block the expression of ALDH. After treating MOSJ-Dkk1 cells with 7-AIPM, $\mathrm{LiCl}$ and $\mathrm{BIO}$ for 5 days, we observed a reduction in ALDH mRNA levels while upregulating Axin2, suggesting that re-establishment of $\mathrm{cWnt}$ activity can reverse the Dkk-1-induced stress response (Figure 3d).

Dkk-1 activity and cWnt-inhibition have been reported to induce a shift from canonical to noncanonical Wnt (ncWnt) signaling, resulting in upregulation of JNK activity, ${ }^{31-34}$ and this process has been reported to increase malignancy of prostate $^{12}$ and hepatocellular carcinoma cell lines. ${ }^{35}$
As $A L D H 1 A 1$ expression can be upregulated by Jun/AP-1 complexes on the $A L D H 1 A 1$ promoter, ${ }^{36}$ we speculated that Dkk-1 might upregulate ALDH expression by promoting ncWnt/JNK signaling. To test this hypothesis, MOSJ-Dkk1 cells were exposed to AP-1 inhibitors nordihydroguaiareticacid (NDGA) and curcumin. Exposure to either inhibitors reduced expression of ALDH1A1 and also ALDH1A7 (Figure $3 e$ ). Furthermore, immunoblotting confirmed upregulation of JNK phosphorylation (Figure 3f). Noncanonical Wntsignalling has been reported to activate JNK through the Rac1/planar-cell-polarity (PCP) or the Ror2 receptor pathways via activation map-kinase-kinase-7 (MKK7). ${ }^{37}$ When screened by PCR, we found Ror2 was not expressed (Figure $3 \mathrm{~g}$ ) and MKK7 phosphorylation was not upregulated (Supplementary Figure S3c), thus eliminating Ror2/MKK7 as a potential mechanism. In contrast, MKK4 phosphorylation was upregulated in MOSJ-Dkk1 cells with an associated upregulation of phospho-p38. These data were expected given that MKK4 phosphorylates both JNK and p38, whereas MKK7 is specific to JNK. ${ }^{38}$ The activation of MKK4 rather than MKK7 suggested a PCP-like ncWnt pathway driven by Rac1/ RhoA signaling was responsible for the observed effects of Dkk-1 on MOSJ-cells. ${ }^{39}$ In support of this interpretation, we found the PCP-pathway components Daam1 and RhoA ${ }^{40}$ to be transcriptionally upregulated in MOSJ-Dkk1 cells (Figure 4a). We were also able to demonstrate that treatment of MOSJ-Dkk1 cells with a RhoA inhibitor reduced JNK phosphorylation levels (Figure 4b) and subsequently $A / d h 1 A 1$ and $-1 A 7$ transcription (Figure $4 \mathrm{c}$ ). Together, the data indicate that ALDH1 is upregulated by a JNK/PCP-like pathway when cWnt activity is blocked by Dkk-1 (Figure 4d).

To further confirm a role for JNK and ALDH in supporting OS cell survival, parental MOS-J cells were transfected with constructs encoding constitutively expressing human c-Jun or ALDH1A1. After transfection, the cells were subjected to postconfluence for 6 days and then analyzed by using flow cytometric apoptosis assay. ALDH and c-Jun overexpression resulted in a reduced proportion of apoptotic cells (Figure 5a). An increase in the proportion of Aldefluor-positive cells was also observed in cultures that transiently expressed the ALDH1A1 and c-Jun constructs (Figure 5b).

Effect of Dkk-1 on the tumorigenicity of MOS-J cells. To test the effects of Dkk-1 on MOS-J tumorigenicity in vivo, $1 \times 10^{6}$ dsRed-labeled MOSJ-Dkk1 or -pLenti cells were injected paratibially into 8-week-old nu/J mice. Over a period of 5-7 weeks, animals were observed for tumor development using a fluorescence imaging system (Figures 6a and b). The tumors in MOSJ-pLenti mice were barely detectable

Figure 2 MOSJ-Dkk1 cells have improved survival capability through upregulation of ALDH. (a) Cell-cycle analysis demonstrates that post-confluent MOSJ-Dkk1 cells actively cycle with a substantial proportion of cells in $S / G_{2} / M$ phase, whereas the majority of MOSJ-pLenti cells remain in $G_{0} / G_{1}$ phase. (b) $Q u a n t i f i c a t i o n$ of data presented in panel a. (c) Flow cytometric viability assays demonstrate that post-confluent MOSJ-Dkk1 cells are more viable than MOSJ-pLenti controls (lower left quadrants) and are more resistant to apoptosis as demonstrated by a decrease in the proportion of Annexin V-positive cells (lower right quadrants). (d) Quantification of data presented in panel c. Data were analyzed with $t$-test after arcsine transformation and means \pm S.D. are displayed. ${ }^{* \star} P<0.01$. (e) Transcription of ALDH isoenzymes $1 \mathrm{~A} 1$ and $1 \mathrm{~A} 7$ is upregulated in MOSJ-Dkk1 cells when measured by microarray or qRT-PCR. (f) ALDH1 enzyme activity in MOS-J cells was confirmed by using the Aldefluor assay. Background fluorescence levels were defined by treatment with the ALDH inhibitor DEAB. Note that all MOSJ-Dkk1 cells harbor DEAB-sensitive ALDH activity resulting in a shift in fluorescence intensity. This shift is not evident with MOSJ-pLenti cells where only a subpopulation is ALDH-positive. Representative images of three independent experiments are shown. $(\mathbf{g}, \mathbf{h})$ The protective effect of ALDH could be antagonized in a dose-dependent manner by treatment with inhibitors chloramphenicol $(\mathbf{g})$ and DEAB (h). All experiments were performed in triplicates. Data were analyzed with ANOVA and Tukey post test. Means \pm S.D. are displayed. ${ }^{*} P<0.05,{ }^{* \star} P<0.01,{ }^{\star * \star} P<0.005$ 


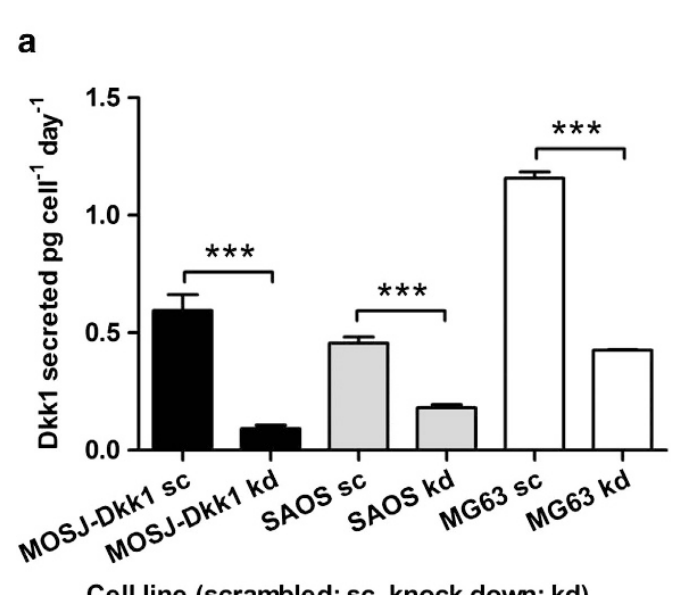

Cell line (scrambled: sc, knock down: kd)

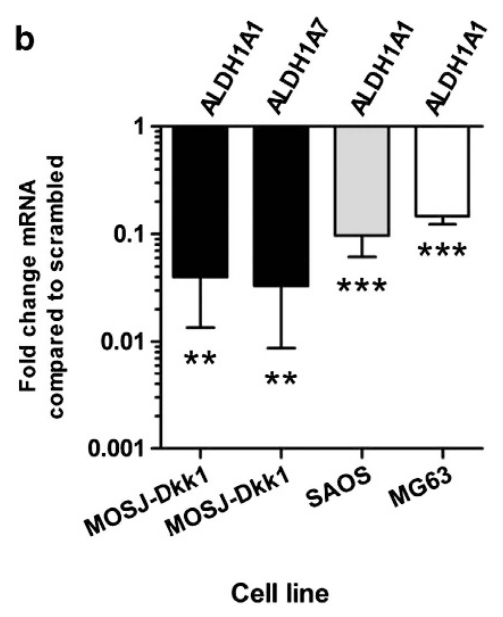

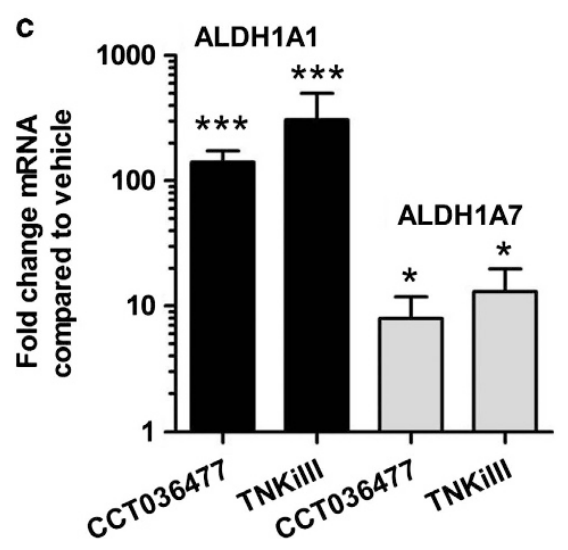
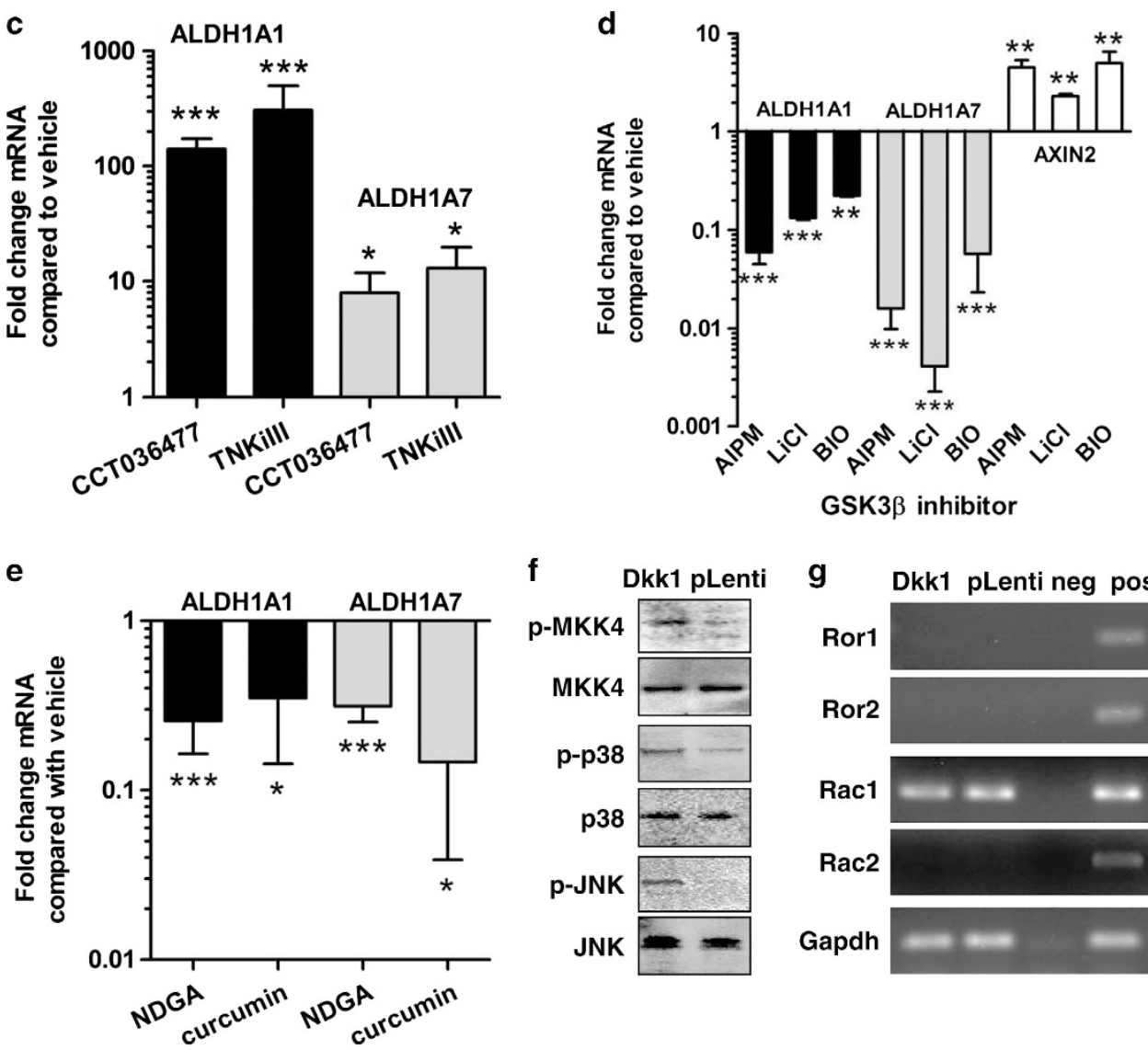

f

Dkk1 pLenti $\quad$ g

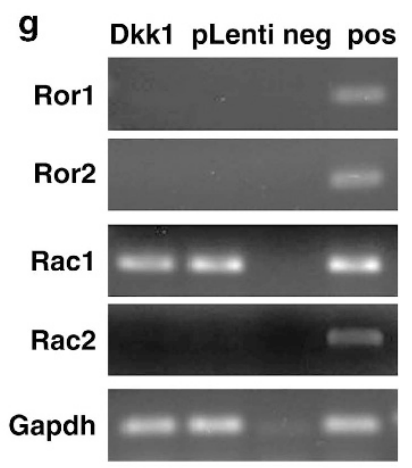

\section{AP1 inhibitor}

Figure 3 Inhibition of cWnt by Dkk-1 results in increased ALDH expression by activating ncWnt-signaling and JNK. (a) Treatment of MOSJ-Dkk1 or human OS cell lines (SAOS and MG63) with anti-Dkk-1 siRNA reduces Dkk-1 secretion when media is measured by ELISA (see also Supplementary Figure S3a). (b) Reduced Dkk-1 secretion results in transcriptional downregulation of ALDH isoforms. (c) Inhibition of cWnt-signaling in MOSJ-pLenti cells with a $\beta$-catenin antagonist (CCT036477) or a tankyrase inhibitor (TNKilll) causes upregulation of ALDH transcription and improved post-confluent viability (see also Supplementary Figure S3b). (d) Re-establishing cWnt-signaling in MOSJ-Dkk1 cells with inhibitors of GSK3 $\beta$ causes transcriptional inhibition of ALDH1A1 and -1A7 while upregulating AXIN2, a marker of cWnt-signaling. (e) AP-1 inhibitors NDGA and curcumin reduce ALDH1A1 and -1A7 transcription, demonstrating that expression of the enzymes is regulated by the Jun transcription factor. (f) Western blots demonstrating that MOSJ-Dkk1 cells have elevated levels of phosphorylated MKK-4, p38 and JNK but not MKK7 (see Supplementary Figure S3c). (g) absence of Ror2 receptor expression in MOS-J cells excludes this pathway. CDNA from E12.5 mouse embryos was used as positive control. All experiments were performed in triplicates. Expression levels were compared with vehicle-treated cells. Data were analyzed with $t$-test and means \pm S.D. are displayed. ${ }^{*} P<0.05,{ }^{* \star} P<0.01,{ }^{* \star *} P<0.005$

until 7 weeks, when single circumscribed nodules could be identified. In contrast, MOSJ-Dkk1 cells generated tumors that became visible after 3 weeks and were readily detectable as diffuse and extensive multi-lobular structures. Generally, animals that received MOSJ-Dkk1 cells had to be euthanized after week 5 because tumors reached the limits 
a

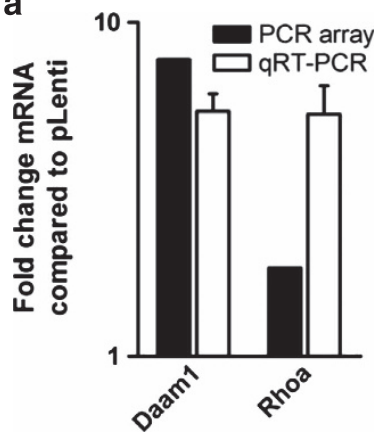

b

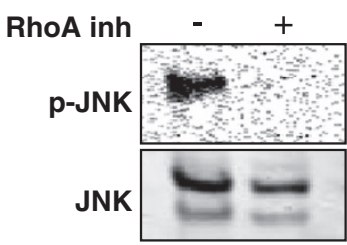

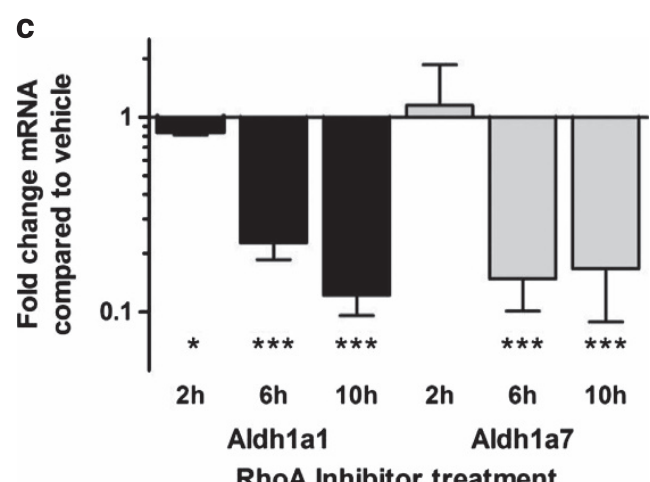

d

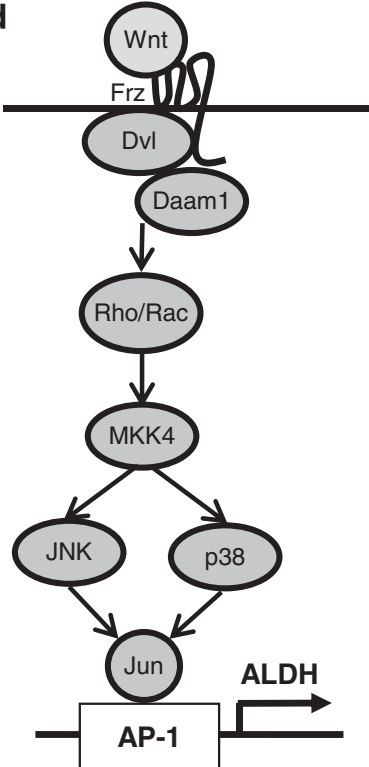

Figure 4 Involvement of the RhoA pathway. (a) Transcription of Daam1 and Rhoa is upregulated in MOSJ-Dkk1 cells when measured by PCR array or qRT-PCR. (b, c) Treatment of MOSJ-Dkk1 cells with a RhoA inhibitor reduces JNK phosphorylation levels after $2 \mathrm{~h}$ (b) and subsequently Aldh1A1 and $-1 A 7$ transcription levels (c). (d) The proposed PCP-like pathway suggesting that ALDH is activated by ncWnt-mediated modulation of JNK. Data were analyzed with $t$-test and means \pm S.D. are displayed. ${ }^{*} P<0.05,{ }^{* *} P<0.005$

of the institutional tumor burden policy of $1 \mathrm{~cm}^{3}$. Control animals were maintained for the full 7 -week duration.

Hindlimbs of the mice were scanned using $\mu \mathrm{CT}$ to assess bone involvement and measure tumor volume. The scans indicated that control MOSJ-pLenti cells formed radio-dense tumor nodules in the soft tissue that exhibited minimal involvement with the host bone (Figure $6 \mathrm{c}$ ). In contrast, MOSJ-Dkk1 tumors were much larger and caused lytic bone destruction that was particularly evident in the fibulas (Figure $6 \mathrm{~d}$ ). As such, fibulas had a reduced proportion of mineralized tissue when analyzed volumetrically (Figure 6j).

When visualized by $\mu \mathrm{CT}$ (Figures $6 \mathrm{e}-\mathrm{h}$ ) and histology (Figure 7), MOSJ-Dkk1 cells had infiltrated into the host tissue to the extent that prohibited volumetric measurement of tumors. Therefore, an indirect method was employed to estimate the volumes of the tumor (see Supplementary Materials and Methods). In brief, a ROI was defined for each limb where the proximal and distal limits of the tumor were defined (Figure 6l). The total tissue volume within the ROI was then calculated and compared with an anatomically equivalent $\mathrm{ROI}$ in the unaffected contralateral limb. By this method, excess volume contributed by the tumor and stroma could be ascertained and, as a result, MOSJ-Dkk1 tumors were found to be significantly larger than MOSJ-pLenti controls (Figure 6i). Although the longitudinal dimensions were greater in MOSJ-Dkk1 tumors (Figure 6l), the volumes of the corresponding contralateral ROls did not differ significantly (Figure 6i). Histomorphometric analysis showed a reduction in trabecular thickness of MOSJ-Dkk1-affected tibias (Figure 6k) and an increased inner diameter (Supplementary Figure S4), in accordance with the more osteolytic phenotype of MOSJDkk1 cells.

To characterize the pathology in more detail, serial sections were stained with trichrome and inspected by a clinical pathologist with expertise in OS. When examined histologically, MOSJ-pLenti cells formed small ossified nodules that displaced the surrounding muscle tissue but did not substantially affect the bone (Figures 7a-d). In contrast, MOSJ-Dkk1 tumors exhibited aggressive growth behavior, lytic bone involvement and destructive soft tissue invasion (Figures $7 \mathrm{e}-\mathrm{h})$. Of particular note was the lack of differentiation of MOSJ-Dkk1 tumors, resulting in homogeneous masses of 

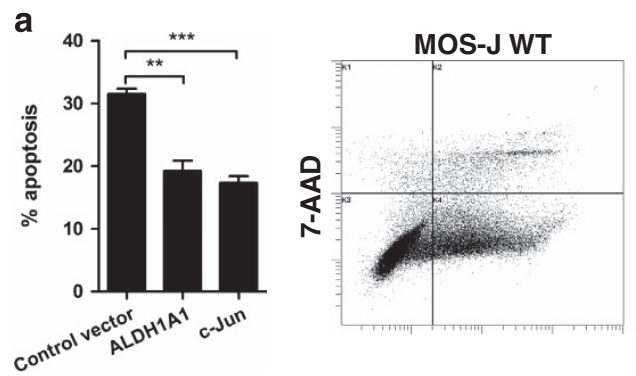

b

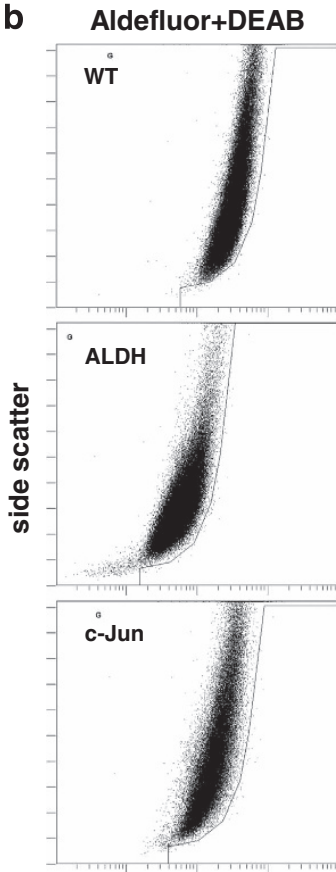

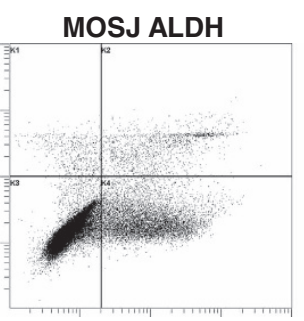

annexin-V PE

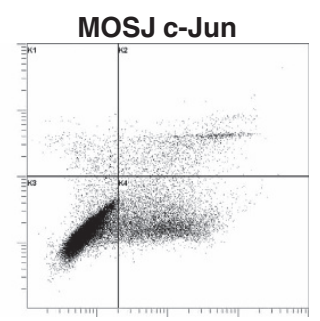

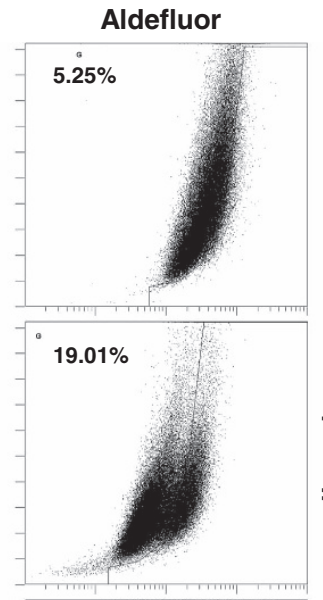

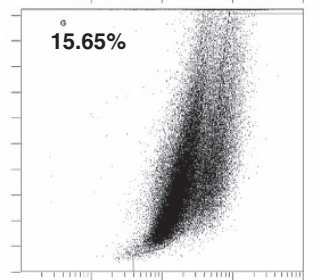

fluorescence intensity

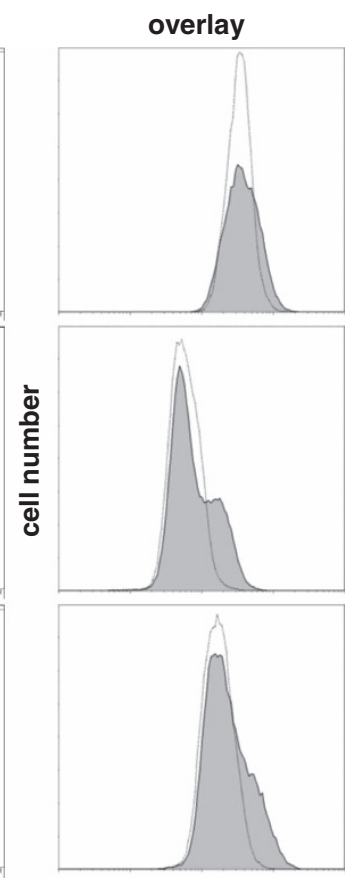

Figure 5 Constitutive expression of c-Jun or ALDH mimics the effect of Dkk-1 in parental MOS-J cells. Plasmid constructs encoding human ALDH1A1 or c-Jun were transfected into parental MOSJ cells and subjected to post-confluent tissue culture. (a) Flow cytometric apoptosis assays demonstrating a reduced proportion of apoptotic cells in cultures that received ALDH1A1 or c-Jun cDNA when compared with controls harboring an equivalent vector control. Data were analyzed by ANOVA and Tukey post test after arcsine transformation and means \pm S.D. are displayed. ${ }^{* \star} P<0.01,{ }^{\star \star \star} P<0.005$. (b) Aldefluor assay shows increased ALDH activity of transfectants when compared with the parental cells

spindle-like cells, a phenomenon usually associated with more malignant OS. In contrast, MOSJ-pLenti tumors exhibited areas of bone, adipose and cartilage differentiation consistent with the underlying osteochondrosarcoma phenotype (Figures $7 d$ and $h$ ). The same growth pattern was evident in the femurs (Supplementary Figure S5).Taken together, these results demonstrate that MOSJ-Dkk1 tumors were larger and substantially more destructive than their MOSJpLenti controls.

\section{Discussion}

Herein, we explored the effects of a single constitutively expressed gene, human Dkk-1, on the growth of the murine OS cell line MOS-J. Our most striking observation was the role of Dkk-1 in enhancing proliferation and survival of MOSJDkk1 cells when subjected to metabolic stress. These results were unexpected, given the classical role of $\mathrm{cWnt}$ in driving oncogenesis in numerous tissues. ${ }^{41}$ Dkk-1 expression resulted in the activation of JNK, which in turn caused transcriptional activation of two isoenzymes of the ALDH1 family. Given the inhibitory effects of NGDA and curcumin and a recent report that ALDH1A1 expression is activated by Jun transcription factors, the results suggest that JNK activates Jun/AP-1 complexes in the ALDH1 promoters.

Our data provide a novel explanation for the various and sometimes contradicting effects of Dkk-1 and Wnt-signaling on bone tumor biology. They suggest that catastrophically high levels of cWnt-inhibitor shift the balance in favor of ncWnt-signaling. Mechanisms that explain the shift between cWnt- and ncWnt-signaling are yet to be comprehensively characterized, but our data are in agreement with a recently published study by Killick et al. ${ }^{42}$ who report a link between Dkk1 and PCP-JNK in a model of Alzheimer's disease. ${ }^{42}$ The downstream effect, as initially observed by Matushansky et al. and Thudi et al., is activation of JNK signaling and the initiation of a more malignant phenotype. ${ }^{11-12}$ Our observations are similar in that we confirm that, through JNK activation, Dkk-1 

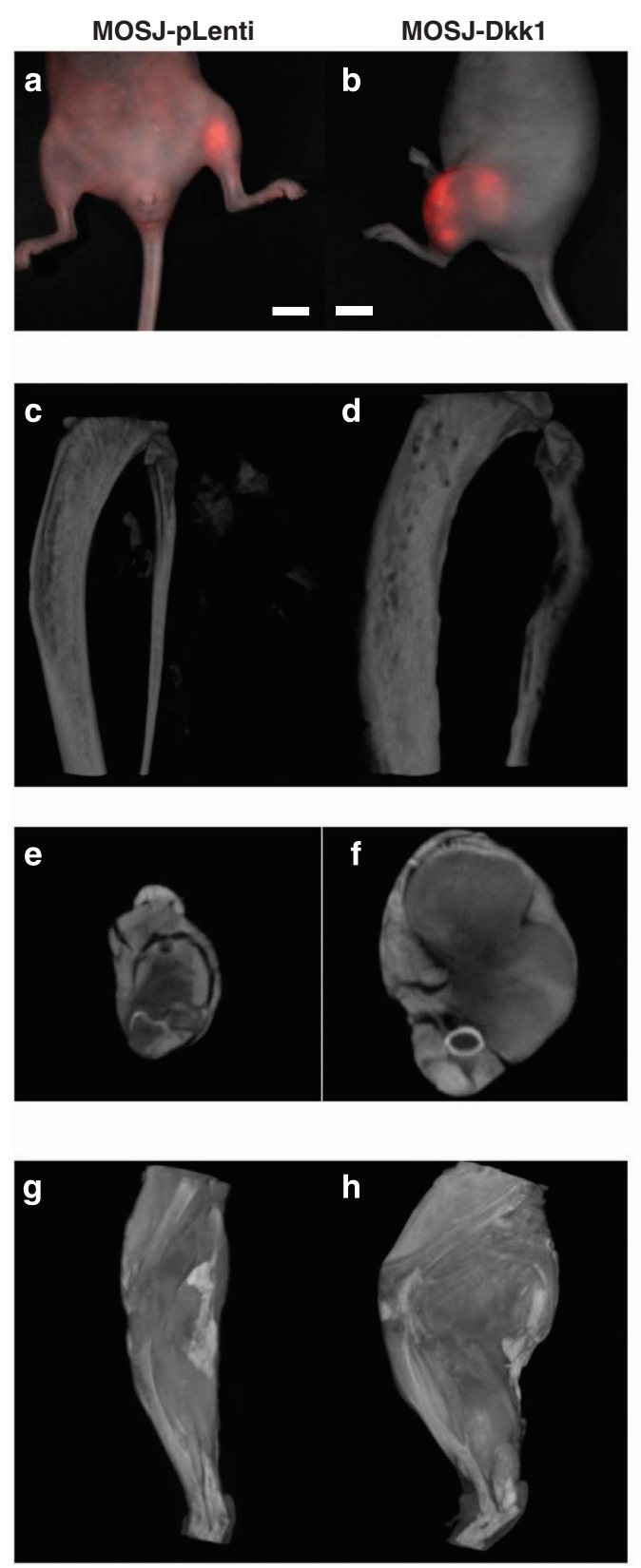

Figure 6 Tumor formation in vivo. Representative images of tumors resulting from the injection of dsRed-labeled MOSJ-pLenti- or MOSJ-Dkk1 cells in nude mice. (a, b) MOSJ-pLenti tumors form circumscribed nodules after 7 weeks (a), whereas MOSJ-Dkk1 cells generate larger tumors with extensive multi-lobular structures (b, 5 weeks). Bars: $1 \mathrm{~cm}$. (c, d) Reconstructions of $\mu \mathrm{CT}$ scans from the affected tibias and fibulas. MOSJ-pLenti cells formed radio-dense tumor nodules in the soft tissue and exhibited minimal involvement with the host bone (c). MOSJ-Dkk1 tumors caused lytic bone destruction and remodeling that was most evident in the fibulas (d). (e, f) Axial reconstructions of contrast stained scans of MOSJ-pLenti (e) and MOSJ-Dkk1 (f) harboring limbs. (g, h) Three dimensional reconstructions of $\mu$ CT whole limb scans after contrast staining demonstrate the extent of soft tissue involvement in MOSJ-Dkk-1 tumors (h) compared with pLenti-MOSJ harboring limbs that have a normal appearance (g). (i) Total tissue volume in ROls containing the tumor as compared with an anatomically equivalent ROI on the unaffected contralateral side. The volume of tissue in the MOSJ-pLenti ROI is equivalent to the contralateral limb, whereas, in the case of MOSJ-Dkk1 tumors, the affected limbs are approximately twofold larger than the contralateral side. Note also that volumes between MOSJ-pLenti and -Dkk1 contralateral limbs do not significantly differ in spite of the slightly increased length of the MOSJ-Dkk1 ROI. (j) Volumetric calculation of bone in the fibulas confirmed increased osteolysis in MOSJ-Dkk1 recipients. (k) The trabecular thickness (Tr. Th.) of MOSJ-Dkk1 affected tibias is decreased, suggesting a more osteolytic phenotype. See also Supplementary Figure S4. (I): Proximal/distal involvement of tumors as a measure of the length of the limb affected by tumor tissue. Results displayed as box and whisker plots with the boxes representing the 25-75th percentiles, the center line representing the median, and the whiskers representing the full range of data. $(n=4) ;{ }^{*} P<0.05,{ }^{\star \star} P<0.01,{ }^{\star \star \star} P<0.001, n s P>0.05$

exacerbates the malignancy of tumor cells. However, they are novel in proving that this effect occurs through enhanced resistance to metabolic stress through $\mathrm{ALDH} 1$ rather than dysregulation of mitosis and that the mechanism responsible is likely to be through a RhoA/Rac-dependent PCP-like ncWnt pathway.

ALDH1, a marker previously associated with the CSCphenotype, ${ }^{43-44}$ was recently found to have a role in drug 

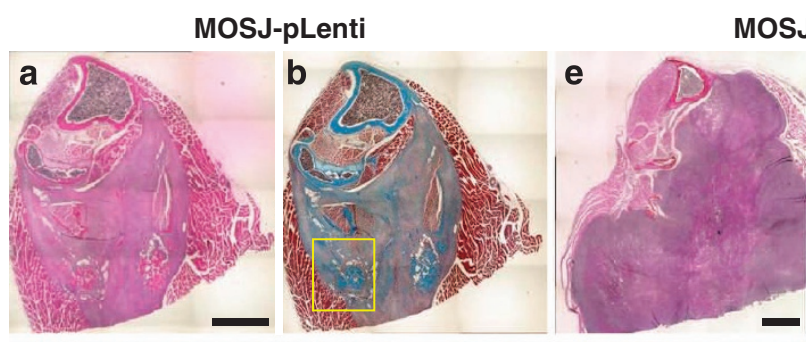

MOSJ-Dkk1
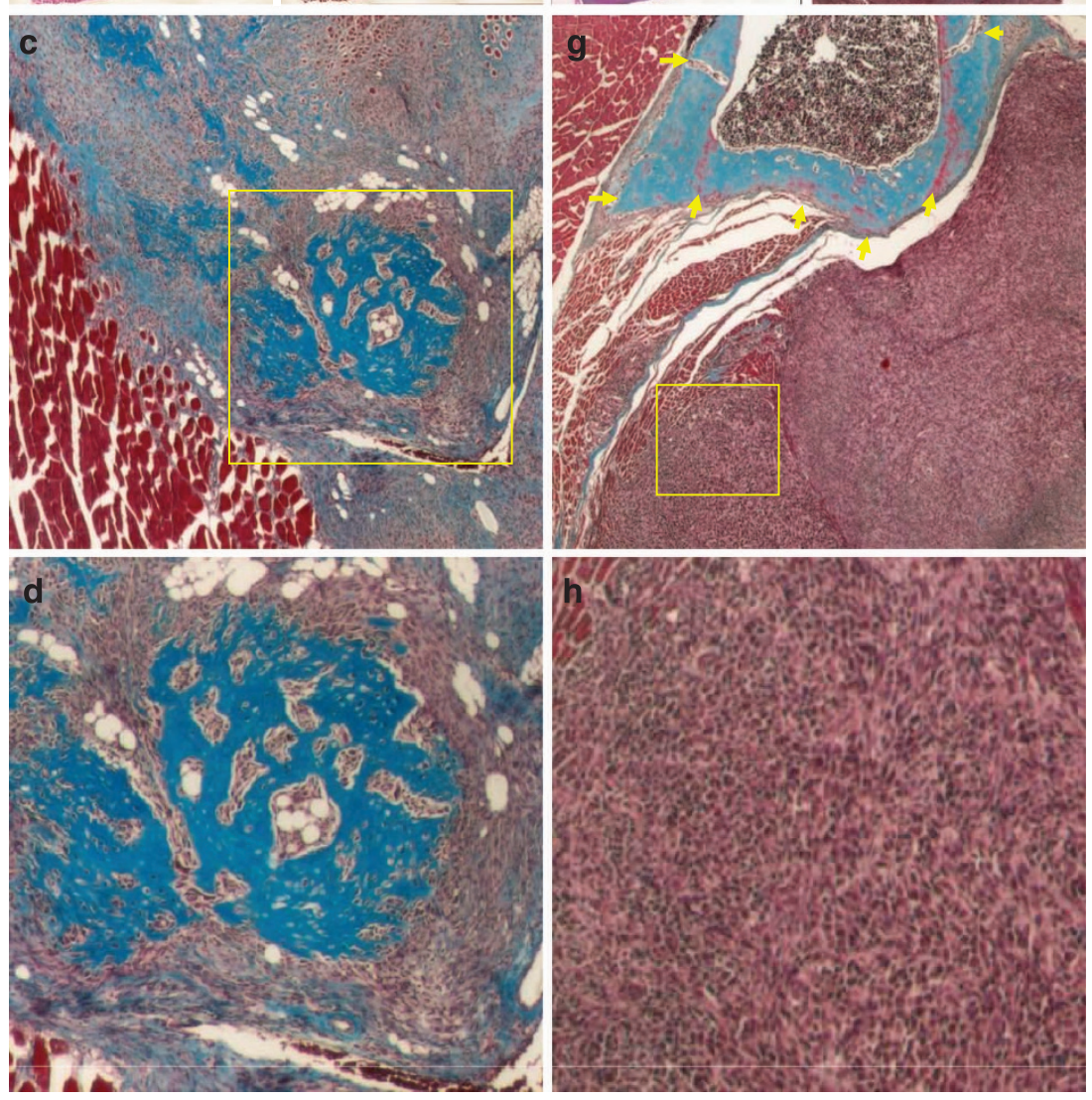

Figure 7 Histology of tumors and bone lesions. Serial sections of MOS-J tumors were stained with hematoxylin and eosin (a, e) and trichrome (b-d, $\mathbf{f}-\mathbf{h})$. MOSJ-pLenti cells form small ossified nodules and tumors that displaced the surrounding muscle tissue and did not substantially affect the bone surface (a). Areas of cartilage, bone and fat differentiation consistent with the underlying osteochondrosarcoma phenotype are evident (b-d). In contrast, MOSJ-Dkk1 tumors exhibited aggressive growth behavior (e, f), soft tissue invasion, and lytic bone involvement (arrows, $\mathbf{g}$ ). Note the complete lack of differentiation resulting in highly homogeneous masses of more primitive spindle-like cells (h). See also Supplementary Figure S5. Bars: $1 \mathrm{~mm}$

resistance and enhanced survival in OS cells. ${ }^{45-46}$ Our observations that Dkk-1 induces expression of ALDH1A1 and ALDH1A7 are consistent with this hypothesis. It should be noted, however, that, in human OS, the effect is probably mediated through ALDH1A1 only, given that $A L D H 1 A 7$ is not present in human cells, even though it shares substantial sequence similarity with $A L D H 1 A 1 .^{47}$

In a study of soft tissue sarcomas, high Dkk-1 levels correlated with poorly differentiated and more aggressive sarcomas. ${ }^{48}$ Our results support these observations, demonstrating that Dkk-1 alone can convert a relatively benign and well-differentiated OS cell line ${ }^{17}$ into a more aggressive and primitive form. ${ }^{49}$ Depending on the underlying tissue of origin, cancers with high levels of Dkk-1-expression have been reported both as being pro- and antimetastatic. ${ }^{50}$ Although being more aggressive, none of the animals showed signs of metastasis when we examined the lungs. Nevertheless, in many animal models of metastatic OS disease, the primary tumor has to be excised to artificially extend the time window needed for lung metastases to develop. ${ }^{51}$ As the MOSJ-Dkk1 variant turned out to be prohibitively aggressive, one could speculate that any existing lung metastases were too small to observe before the ethical end point. Therefore, extra work is required to explore the role of Dkk-1 in OS metastasis.

With the exception of tibial trabecular thickness, medullary canal diameter and fibula volume, differences in the quality of bone adjacent to the tumors were mostly qualitative, with the replacement bone around MOSJ-Dkk1 tumors consisting of cancellous, poor quality tissue. This is likely caused by the mixed osteoclastic/osteoblastic nature of OS and the rapid remodeling that occurs. Secondary bone tissue is likely to be susceptible to risk of pathologic fractures, and it also provides 
a superior substratum for osteoclast activity. Indeed, the total bone area adjacent to the MOSJ-Dkk1 tumor was densely populated by osteoclasts.

In this study, we demonstrate that expression of a Wntinhibitor, Dkk-1, is capable of activating a potent growth and survival pathway in OS cells. The effects of Dkk-1 on cellular physiology were multi-faceted, involving decreased differentiation potential, increased proliferation and enhanced osteolytic capacity. Surprisingly, Dkk-1 also triggered a potent survival response mediated by ncWnt/JNK activation. This in turn resulted in expression of the detoxifying enzyme and CSC-marker ALDH1, equipping the cells with enhanced resistance to metabolic stress. Resultant tumors were large, poorly differentiated and highly destructive.

Strategies to judiciously re-establish the cWnt axis through pharmacological inhibition of GSK3 $\beta,{ }^{52}$ immunosequestration of $D k k-1^{53,54}$ or direct inhibition of ALDH activity with chloramphenicol or disulfiram ${ }^{25}$ could lead to promising adjunct therapies for OS and possibly other types of bone tumor. These strategies are expected to reduce the CSC-pool and render tumors more susceptible to conventional antimitotic therapies.

\section{Materials and Methods}

Tissue culture. (See Supplementary Materials and Methods for details) We expanded the murine OS cell line MOS-J ${ }^{17}$ (The Jackson Laboratory, Bar Harbor, $\mathrm{ME}, \mathrm{USA}$ ) in medium consisting of $\alpha \mathrm{MEM}, 10 \%$ fetal bovine serum (FBS), 100 units $/ \mathrm{ml}$ penicillin $\mathrm{G}$ and $100 \mu \mathrm{g} / \mathrm{ml}$ streptomycin (Invitrogen, Carlsbad, CA, USA). Cell numbers and viability were assessed using trypan blue staining (GIBCO/ Invitrogen). Human OS cell lines SAOS and MG63 were acquired from the American Type Culture Collection (Manassas, VA, USA) and cultured in the same manner as MOS-J cells.

Transfection of MOS-J cells. In order to generate a humanized mouse model of Dkk1-induced bone disease, we introduced the human Dkk-1 gene into MOS-J cells via lentiviral particles produced using the pLenti6/V5 Directional TOPO Cloning Kit and ViraPower Lentiviral Expression System (Invitrogen). For nonviral transfection, human Dkk-1 cDNA was cloned into the pLenti6.1 plasmid (Invitrogen) by standard methods.

Aldefluor staining. To confirm ALDH activity in the cells, one million cells were labeled by the Aldefluor assay kit (Aldagen, Durham, NC, USA) following the manufacturer's recommendations and analyzed using a FC500 flow cytometer (Beckman Coulter, Miami, FL, USA). Cells treated with the ALDH-inhibitor diethylaminobenzaldehyde (DEAB) served as an internal control for identifying background signals.

Inhibition of GSK3 $\beta$. In order to re-establish cWnt-signaling, MOSJ-Dkk1 cells were treated with GSK3 $\beta$ inhibitors of varying reported specificities 7-AIPM, 6-bromoindirubin- 3'-oxime (BIO; both Calbiochem EMD Millipore, Billerica, MA USA) and LiCl (Alexis Biochemicals, San Diego, CA, USA) as published earlier. ${ }^{52,55}$

Animal care and use. All animal experiments were performed in accordance with animal use protocols approved by the Tulane University and Scott \& White Hospital Animal Care and Use committees. Female 8-week-old nu/J mice were acquired from Jackson Laboratories. Mice were housed in groups of four per cage under specific pathogen-free conditions. They were allowed to access sterile standard mouse chow and water ad libitum.

Orthotopic implantation of MOS-J cells and OS model. Under isoflurane anesthesia, one million dsRed labeled MOSJ-Dkk1 or MOSJ-pLenti cells were injected against the posterior surface of the tibia in $100 \mu \mathrm{l}$ of plasma (Sigma-Aldrich, St. Louis, MO, USA) containing thromboplastin (Bio/Data Corporation, Horsham, PA, USA). To follow tumor growth, animals were imaged using a Maestro fluorescence imaging system (Perkin Elmer, Waltham, MA, USA) and software (version 2.6, Cambridge Research \& Instrumentation, Hopkinton,
MA, USA). After 7 weeks or when institutional tumor burden criteria were met, mice were euthanized by terminal exsanguination under deep anesthesia. Animals were perfused with excess PBS and formalin, and legs and lungs were collected.

Histology. After $48 \mathrm{~h}$ fixation in $10 \%$ neutral buffered formalin, tissues were transferred to Carson's fixative and processed as described elsewhere. ${ }^{21}$

Micro-CT $(\mu \mathbf{C T})$. Fixed hindlimbs were scanned using a specimen $\mu \mathrm{CT}$ scanner (Skyscan 1174, Bruker-microCT, Kontich, Belgium) set at $50 \mathrm{kV}$ and $800 \mu \mathrm{A}$ to perform bone histomorphometry, assess bone damage and measure tumor volume as described earlier. ${ }^{56}$

Statistical analysis. Statistical tests and data plotting were performed using GraphPad Prism (ver 5.00 for Windows, La Jolla, CA, USA). ELISA standard curves and values were calculated with ReaderFit (http://www.readerfit.com). Data involving ratios were statistically tested on arcsine-transformed data and post-analyzed by Tukey's or Dunnett's method. Single means were compared using $t$-test. Data were regarded significant, if $P$ values were $<0.05$.

Microarray data have been deposited in NCBl's Gene Expression Omnibus and are accessible through GEO Series accession number GSE43112 (http:// www.ncbi.nlm.nih.gov/geo/query/acc.cgi?acc=GSE43112).

\section{Conflict of Interest}

The authors declare no conflict of interest.

Acknowledgements. We thank Katie Coble, BS, and Joni Ylostalo, PhD, for help with the microarray analysis, Kent Claypool, BS, for assistance with cell sorting, and Ludvik R. Donner, MD/PhD, for expert advice on tumor histology. This project was funded in part by The Institute for Regenerative Medicine Program Funds from Texas A\&M Health Science Center and Start-Up Funds from Scott\&White Hospital, NIH Grants R21DK071780, P20RR020152, the Louisiana Gene Therapy Research Consortium, Scott\&White Hospital Research Project Grant 90172, and the International Myeloma Foundation.

\section{Author contributions}

$C A G$ and $U K$ designed research. BHC, CAG, DR, and UK performed research. $\mathrm{CAG}, \mathrm{DR}$, and UK analyzed and interpreted data. CAG and UK wrote the manuscript.

1. Arndt CA, Rose PS, Folpe AL, Laack NN. Common musculoskeletal tumors of childhood and adolescence. Mayo Clin Proc 2012; 87: 475-487.

2. Gregory CA, Reyes E, Whitney MJ, Spees JL. Enhanced engraftment of mesenchymal stem cells in a cutaneous wound model by culture in allogenic species-specific serum and administration in fibrin constructs. Stem Cells 2006; 24: 2232-2243

3. Westendorf JJ, Kahler RA, Schroeder TM. Wnt signaling in osteoblasts and bone diseases. Gene 2004; 341: 19-39.

4. Glass DA 2nd, Bialek P, Ahn JD, Starbuck M, Patel MS, Clevers H et al. Canonical Wnt signaling in differentiated osteoblasts controls osteoclast differentiation. Dev Cell 2005; 8: 751-764.

5. Tian E, Zhan F, Walker R, Rasmussen E, Ma Y, Barlogie B et al. The role of the Wnt-signaling antagonist DKK1 in the development of osteolytic lesions in multiple myeloma. N Engl J Med 2003; 349: 2483-2494.

6. Lee N, Smolarz AJ, Olson S, David O, Reiser J, Kutner R et al. A potential role for Dkk-1 in the pathogenesis of osteosarcoma predicts novel diagnostic and treatment strategies. Br J Cancer 2007; 97: 1552-1559.

7. Hall CL, Daignault SD, Shah RB, Pienta KJ, Keller ET. Dickkopf-1 expression increases early in prostate cancer development and decreases during progression from primary tumor to metastasis. Prostate 2008; 68: 1396-1404.

8. Voorzanger-Rousselot N, Goehrig D, Journe F, Doriath V, Body JJ, Clezardin P et al. Increased Dickkopf-1 expression in breast cancer bone metastases. Br J Cancer 2007; 97: 964-970.

9. Bienz M, Clevers H. Linking colorectal cancer to Wnt signaling. Cell 2000; 103: 311-320.

10. Cai $Y$, Mohseny AB, Karperien M, Hogendoorn PC, Zhou G, Cleton-Jansen AM. Inactive Wnt/beta-catenin pathway in conventional high-grade osteosarcoma. J Pathol 2010; 220: 24-33.

11. Matushansky I, Hernando E, Socci ND, Mills JE, Matos TA, Edgar MA et al. Derivation of sarcomas from mesenchymal stem cells via inactivation of the Wnt pathway. J Clin Invest 2007; 117: 3248-3257. 
12. Thudi NK, Martin CK, Murahari S, Shu ST, Lanigan LG, Werbeck JL et al. Dickkopf-1 (DKK-1) stimulated prostate cancer growth and metastasis and inhibited bone formation in osteoblastic bone metastases. Prostate 2011; 71: 615-625.

13. Guo Y, Rubin EM, Xie J, Zi X, Hoang BH. Dominant negative LRP5 decreases tumorigenicity and metastasis of osteosarcoma in an animal model. Clin Orthop Relat Res 2008; 466: 2039-2045.

14. Kansara M, Tsang M, Kodjabachian L, Sims NA, Trivett MK, Ehrich M et al. Wnt inhibitory factor 1 is epigenetically silenced in human osteosarcoma, and targeted disruption accelerates osteosarcomagenesis in mice. J Clin Invest 2009; 119: 837-851.

15. Navarro D, Agra N, Pestana A, Alonso J, Gonzalez-Sancho JM. The EWS/FLI1 oncogenic protein inhibits expression of the Wnt inhibitor DICKKOPF-1 gene and antagonizes betacatenin/TCF-mediated transcription. Carcinogenesis 2010; 31: 394-401.

16. Rubin EM, Guo Y, Tu K, Xie J, Zi X, Hoang BH. Wnt inhibitory factor 1 decreases tumorigenesis and metastasis in osteosarcoma. Mol Cancer Ther 2010; 9: 731-741.

17. Joliat MJ, Umeda S, Lyons BL, Lynes MA, Shultz LD. Establishment and characterization of a new osteogenic cell line (MOS-J) from a spontaneous C57BL/6J mouse osteosarcoma. In Vivo 2002; 16: 223-228.

18. Gregory CA, Singh H, Perry AS, Prockop DJ. The Wnt signaling inhibitor dickkopf-1 is required for reentry into the cell cycle of human adult stem cells from bone marrow. J Biol Chem 2003; 278: 28067-28078.

19. Bain G, Muller T, Wang X, Papkoff J. Activated beta-catenin induces osteoblast differentiation of $\mathrm{C} 3 \mathrm{H} 10 \mathrm{~T} 1 / 2$ cells and participates in BMP2 mediated signal transduction. Biochem Biophys Res Commun 2003; 301: 84-91.

20. Rawadi G, Vayssiere B, Dunn F, Baron R, Roman-Roman S. BMP-2 controls alkaline phosphatase expression and osteoblast mineralization by a Wnt autocrine loop. J Bone Miner Res 2003; 18: 1842-1853.

21. Zeitouni S, Krause U, Clough BH, Halderman H, Falster A, Blalock DT et al. Human mesenchymal stem cell-derived matrices for enhanced osteoregeneration. Sci Transl Med 2012; 4: 132ra155.

22. Gregory CA, Gunn WG, Peister A, Prockop DJ. An Alizarin red-based assay of mineralization by adherent cells in culture: comparison with cetylpyridinium chloride extraction. Anal Biochem 2004; 329: 77-84.

23. Makia NL, Bojang P, Falkner KC, Conklin DJ, Prough RA. Murine hepatic aldehyde dehydrogenase 1 a1 is a major contributor to oxidation of aldehydes formed by lipid peroxidation. Chem Biol Interact 2011; 191: 278-287.

24. Vasiliou V, Nebert DW. Analysis and update of the human aldehyde dehydrogenase (ALDH) gene family. Hum Genomics 2005; 2: 138-143.

25. Kast RE, Belda-Iniesta C. Suppressing glioblastoma stem cell function by aldehyde dehydrogenase inhibition with chloramphenicol or disulfiram as a new treatment adjunct: an hypothesis. Curr Stem Cell Res Ther 2009; 4: 314-317.

26. Moreb JS, Ucar D, Han S, Amory JK, Goldstein AS, Ostmark B et al. The enzymatic activity of human aldehyde dehydrogenases $1 \mathrm{~A} 2$ and 2 (ALDH1A2 and ALDH2) is detected by Aldefluor, inhibited by diethylaminobenzaldehyde and has significant effects on cell proliferation and drug resistance. Chem Biol Interact 2012; 195: 52-60.

27. Ewan K, Pajak B, Stubbs M, Todd H, Barbeau O, Quevedo C et al. A useful approach to identify novel small-molecule inhibitors of Wnt-dependent transcription. Cancer Res 2010; 70: 5963-5973.

28. Chen B, Dodge ME, Tang W, Lu J, Ma Z, Fan CW et al. Small molecule-mediated disruption of Wnt-dependent signaling in tissue regeneration and cancer. Nat Chem Biol 2009; 5: 100-107.

29. Huang SM, Mishina YM, Liu S, Cheung A, Stegmeier F, Michaud GA et al. Tankyrase inhibition stabilizes axin and antagonizes Wnt signalling. Nature 2009; 461: 614-620.

30. Shultz MD, Kirby CA, Stams T, Chin DN, Blank J, Charlat $O$ et al. $[1,2,4]$ triazol-3ylsulfanylmethyl)-3-phenyl-[1,2,4]oxadiazoles: antagonists of the Wnt pathway that inhibit tankyrases 1 and 2 via novel adenosine pocket binding. J Med Chem 2012; 55: 1127-1136.

31. Pandur $P$, Maurus $D$, Kuhl M. Increasingly complex: new players enter the Wnt signaling network. Bioessays 2002; 24: 881-884.

32. Lee AY, He B, You L, Xu Z, Mazieres J, Reguart N et al. Dickkopf-1 antagonizes Wnt signaling independent of beta-catenin in human mesothelioma. Biochem Biophys Res Commun 2004; 323: 1246-1250.

33. Sun TQ, Lu B, Feng JJ, Reinhard C, Jan YN, Fantl WJ et al. PAR-1 is a Dishevelledassociated kinase and a positive regulator of Wnt signalling. Nat Cell Biol 2001; 3: 628-636.

34. Yan D, Wallingford JB, Sun TQ, Nelson AM, Sakanaka C, Reinhard C et al. Cell autonomous regulation of multiple Dishevelled-dependent pathways by mammalian Nkd. Proc Natl Acad Sci USA 2001; 98: 3802-3807.

35. Tao YM, Liu Z, Liu HL. Dickkopf-1 (DKK1) promotes invasion and metastasis of hepatocellular carcinoma. Dig Liver Dis 2013; 45: 251-257.
36. Makia NL, Amunom I, Falkner KC, Conklin DJ, Surapureddi S, Goldstein JA et al. Activator protein-1 regulation of murine aldehyde dehydrogenase 1a1. Mol Pharmacol 2012; 82: 601-613.

37. Weston CR, Davis RJ. The JNK signal transduction pathway. Curr Opin Cell Biol 2007; 19: $142-149$.

38. Wang J, Xia Y. Assessing developmental roles of MKK4 and MKK7 in vitro. Commun Integr Biol 2012; 5: 319-324

39. Habas R, Dawid IB, He X. Coactivation of Rac and Rho by Wnt/Frizzled signaling is required for vertebrate gastrulation. Genes Dev 2003; 17: 295-309.

40. Schlessinger K, Hall A, Tolwinski N. Wnt signaling pathways meet Rho GTPases. Genes Dev 2009; 23: 265-277.

41. Clevers H, Nusse R. Wnt/beta-catenin signaling and disease. Cell 2012; 149 1192-1205.

42. Killick R, Ribe EM, Al-Shawi R, Malik B, Hooper C, Fernandes $\mathrm{C}$ et al. Clusterin regulates beta-amyloid toxicity via Dickkopf-1-driven induction of the wnt-PCP-JNK pathway. Mol Psychiatry 2014; 19: 88-98.

43. Charafe-Jauffret E, Ginestier C, lovino F, Wicinski J, Cervera N, Finetti P et al. Breast cancer cell lines contain functional cancer stem cells with metastatic capacity and a distinct molecular signature. Cancer Res 2009; 69: 1302-1313.

44. Ginestier C, Hur MH, Charafe-Jauffret E, Monville F, Dutcher J, Brown M et al. ALDH1 is a marker of normal and malignant human mammary stem cells and a predictor of poor clinical outcome. Cell Stem Cell 2007; 1: 555-567.

45. Honoki K, Fujii H, Kubo A, Kido A, Mori T, Tanaka Y et al. Possible involvement of stem-like populations with elevated ALDH1 in sarcomas for chemotherapeutic drug resistance. Oncol Rep 2010; 24: 501-505.

46. Wang L, Park P, Zhang H, La Marca F, Lin CY. Prospective identification of tumorigenic osteosarcoma cancer stem cells in OS99-1 cells based on high aldehyde dehydrogenase activity. Int J Cancer 2011; 128: 294-303.

47. Alnouti $Y$, Klaassen $C D$. Tissue distribution, ontogeny, and regulation of aldehyde dehydrogenase (Aldh) enzymes mRNA by prototypical microsomal enzyme inducers in mice. Toxicol Sci 2008; 101: 51-64.

48. Gibault L, Perot G, Chibon F, Bonnin S, Lagarde P, Terrier P et al. New insights in sarcoma oncogenesis: a comprehensive analysis of a large series of 160 soft tissue sarcomas with complex genomics. J Pathol 2011; 223: 64-71.

49. Fritchie KJ, Goldblum JR, Tubbs RR, Sun Y, Carver P, Billings SD et al. The expanded histologic spectrum of myxoid liposarcoma with an emphasis on newly described patterns: implications for diagnosis on small biopsy specimens. Am J Clin Pathol 2012; 137: 229-239.

50. Menezes ME, Devine DJ, Shevde LA, Samant RS. Dickkopf1: a tumor suppressor or metastasis promoter? Int J Cancer 2012; 130: 1477-1483.

51. Khanna C, Prehn J, Yeung C, Caylor J, Tsokos M, Helman L. An orthotopic model of murine osteosarcoma with clonally related variants differing in pulmonary metastatic potential. Clin Exp Metastasis 2000; 18: 261-271.

52. Krause U, Harris S, Green A, Ylostalo J, Zeitouni S, Lee N et al. Pharmaceutical modulation of canonical Wnt signaling in multipotent stromal cells for improved osteoinductive therapy. Proc Natl Acad Sci USA 2010; 107: 4147-4152.

53. Glantschnig H, Hampton RA, Lu P, Zhao JZ, Vitelli $S$, Huang $L$ et al. Generation and selection of novel fully human monoclonal antibodies that neutralize Dickkopf-1 (DKK1) inhibitory function in vitro and increase bone mass in vivo. J Biol Chem 2010; 285 40135-40147.

54. Yaccoby S, Ling W, Zhan F, Walker R, Barlogie B, Shaughnessy JD Jr. Antibody-based inhibition of DKK1 suppresses tumor-induced bone resorption and multiple myeloma growth in vivo. Blood 2007; 109: 2106-2111.

55. Gregory CA, Perry AS, Reyes E, Conley A, Gunn WG, Prockop DJ. Dkk-1-derived synthetic peptides and lithium chloride for the control and recovery of adult stem cells from bone marrow. J Biol Chem 2005; 280: 2309-2323.

56. Gunn WG, Krause U, Lee N, Gregory CA. Pharmaceutical inhibition of glycogen synthetase kinase-3beta reduces multiple myeloma-induced bone disease in a novel murine plasmacytoma xenograft model. Blood 2011; 117: 1641-1651.

(c) (1) (2) Cell Death and Disease is an open-access journal published by Nature Publishing Group. This work is licensed under a Creative Commons Attribution-NonCommercialShareAlike 3.0 Unported License. To view a copy of this license, visit http://creativecommons.org/licenses/by-nc-sa/3.0/ 